\title{
Smad3 mutant mice develop colon cancer with overexpression of COX-2
}

\author{
YU-PING ZHU, ZHUO LIU, ZHI-XUAN FU and DE-CHUAN LI \\ Department of Colorectal Cancer Surgery, Zhejiang Cancer Hospital, Hangzhou, Zhejiang 310022, P.R. China
}

Received May 12, 2015; Accepted June 29, 2016

DOI: $10.3892 / 01.2017 .5639$

\begin{abstract}
Colon cancer is the second most common cause of cancer-associated mortality in human populations. The aim of the present study was to identify the role of cyclooxygenase-2 (COX-2) in Smad3 mutant mice, which are known to develop colon cancer. Homozygous Smad3 (-/-) mutant mice were generated from inbred and hybrid Smad3 mouse strains by intercrossing the appropriate heterozygotes. Immunohistochemistry with COX-2 antibody was performed throughout this experiment and the data was validated and cross-checked with reverse transcription-polymerase chain reaction (RT-PCR). Homozygous mutant Smad3 mice were generated and the overexpression pattern of COX-2 was identified by immunohistochemistry and validated with RT-PCR. The results of the present study demonstrated a link between the Smad3 mutant mice, colon cancer and COX-2. In addition, the overexpression pattern of COX-2 in Smad3 mutant mice that develop colon cancer was identified.
\end{abstract}

\section{Introduction}

Colon cancer is the only cancer that occurs in men and women with approximately equal frequencies (1). The actual incidence rate of colon cancer was 71,830 men and 65,000 women in the US population during 2014. That is 1 in $21(4.7 \%)$ for men and 1 in $23(4.4 \%)$ for women (2). Furthermore, colon cancer is the second most common cause of cancer-associated mortality in human populations (1). Due to this, it is essential to improve and discover novel colon cancer therapies by understanding the molecular mechanisms that underlie the cancer. In addition, the mortality rate due to colorectal cancer has changed over the past 50 years $(3,4)$. Colorectal cancer mortality rates decreased by $\sim 2 \%$ per year during the 1990 s, and by $\sim 3 \%$ per year over the past decade (2). The reason for this reduction in colorectal cancer

Correspondence to: Dr De-Chuan Li, Department of Colorectal Cancer Surgery, Zhejiang Cancer Hospital, 1 Banshan Road East, Hangzhou, Zhejiang 310022, P.R. China

E-mail: dechuanli23@gmail.com

Key words: colon cancer, cyclooxygenase-2, Smad3, p53 mortality rates is due to the use of standard screening and treatments in all populations (2). Transforming growth factor (TGF) $\beta$ signaling has the ability to inhibit the proliferation of colonic epithelium cells $(5,6)$. TGF $\beta$ signaling is mediated by the Smad family of intracellular proteins (7), namely Smad2, Smad3 and Smad4, which transduce the appropriate signals. Cyclooxygenase-2 (COX-2) is overexpressed in the majority of human colon cancer cases $(8,9)$. COX-2 converts arachidonic acid to prostaglandins and associated eicosanoids, and induces inflammation and cell proliferation $(8,10)$. Due to the significance of Smad3 and COX-2 in colorectal cancer, the present study was designed to investigate the role of COX-2 in Smad3 mutant mice, which are known to develop colon cancer.

\section{Materials and methods}

Generation of Smad3 (-/-) mutant mice. The use of animals in the present study was approved by the Institutional Animal Care and Ethical Committee, which was formed for the purpose of the present study. Homozygous Smad3 (-/-) mutant mice were generated from the inbred and hybrid Smad3 mouse strains by intercrossing the appropriate heterozygotes obtained from the Department of Colorectal Cancer Surgery (Zhejiang Cancer Hospital, Zhejiang, China) (4). Normal mice obtaiend from the Department of Colorectal Cancer Surgery (Zhejiang Cancer Hospital) were used as a control. Animals were housed in filter-top metal cages and maintained in a $12 / 12 \mathrm{~h}$ light/dark cycle, as previously described (11). Mice were house at $20-22^{\circ} \mathrm{C}$, in a humidity of $50-60 \%$. Water and food were available ad libitum and the mice were handled according to international ethical regulations (12). Female mice aged 22 weeks were used in the present experiments, with an average weight of 10-14 g. The animals were observed twice a day and subjected to weighing once a week. In the present study, 12 homozygous Smad3 (-/-) and 6 control mice were used.

Whole mount in situ hybridization. Homozygous Smad3 (-/-) E11.5 embryos were dissected out of 24-week-old female mutant mice as previously described (13), fixed for $30 \mathrm{~min}$ at room temperature in $4 \%$ paraformaldehyde in phosphate-buffered saline (PBS), washed twice with PBS, and incubated in X-gal staining solution (Sigma-Aldrich; EMD Millipore, Billerica, MA, USA) to determine the colonic expression pattern (14). 


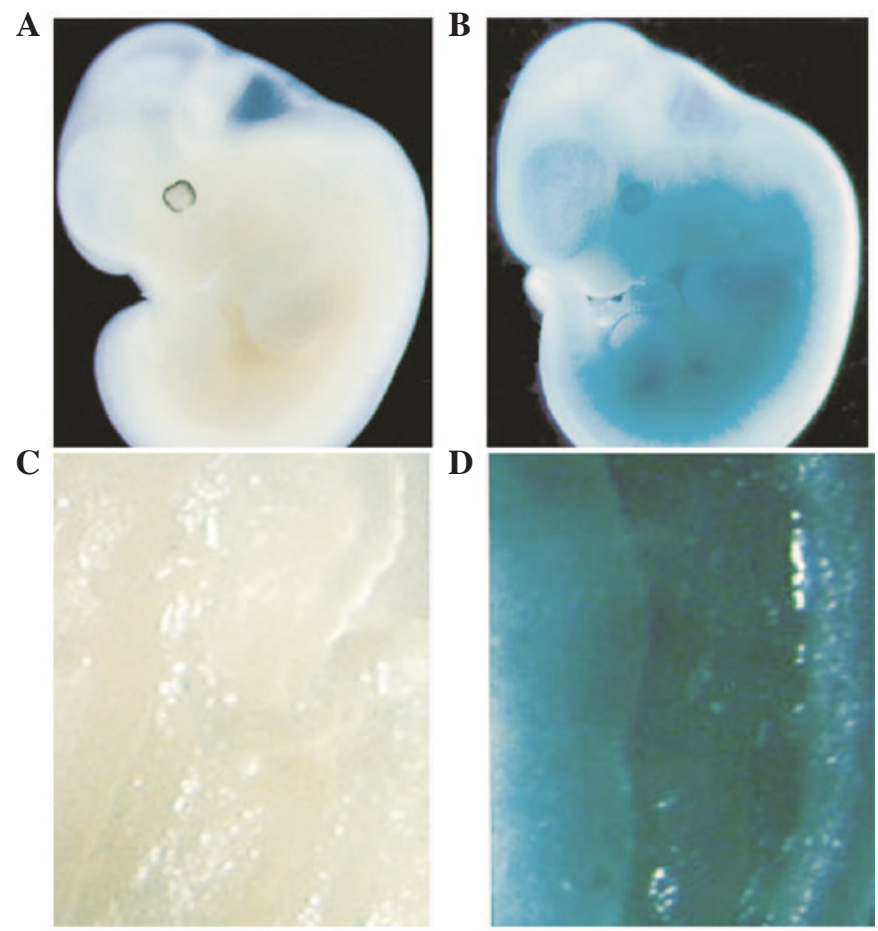

Figure 1. The expression pattern of Smad3 in normal and homozygous mutant Smad3 (-/-) mice was identified by whole-mount in situ hybridization of embryos at day 11.5 (A) Whole mount in situ hybridization of control E11.5 embryo taken from a healthy mouse. (B) Whole mount in situ hybridization of homozygous mutant Smad3 mouse E11.5 embryo. (C) Whole mount in situ hybridization of control colon taken from a healthy mouse. (D) Whole mount in situ hybridization of homozygous mutant Smad3 mouse colon. Representative images from three replicate experiments are presented here.

Immunohistochemistry. A total of 6 normal (3 samples) and Smad3 (-/-) mutant mouse (3 samples) samples were collected, formalin-fixed and paraffin-embedded using standard protocol (15). The 22-week-old mice were anesthetized with pentobarbital sodium $(60 \mathrm{mg} / \mathrm{kg}$, intraperitoneally; Sigma-Aldrich; EMD Millipore) prior to surgery. Tissue sections $(7 \mu \mathrm{m})$ were deparaffinized (with xylene; Sigma-Aldrich; EMD Millipore) and hydrated (with ethanol; Sigma-Aldrich; EMD Millipore). Antigens were retrieved by Tri-sodium citrate treatment (pH 6.0; Sigma-Aldrich; EMD Millipore). Endogenous peroxides and nonspecific immune staining were blocked by hydrogen peroxide and $10 \%$ fetal bovine serum (Sigma-Aldrich; EMD Millipore), respectively. The sections were subsequently incubated overnight at $4^{\circ} \mathrm{C}$ with primary anti-COX-2 antibody (polyclonal goat; dilution, 1:100; catalog no., SAB2500267; Sigma-Aldrich; EMD Millipore). Following incubation with primary antibody, tissue sections were washed with PBS and incubated with secondary antibodies conjugated to horseradish peroxidase (polyclonal rabbit anti-goat; dilution, 1:10,000; catalog no., ab6741; Abcam, Cambridge, MA, USA) for $1 \mathrm{~h}$ at room temperature. The washed slides were developed with 3,3'-diaminobenzidine substrate. The prepared slides were counterstained with Mayer's hematoxylin (Sigma-Aldrich; EMD Millipore), mounted with DPX and observed under a Nikon Ti-S fluorescence microscope at $\mathrm{x} 4$ and $\mathrm{x} 20$ magnification.

Reverse transcription-polymerase chain reaction ( $R T-P C R)$ analysis. For RT-PCR analysis, RNA was isolated from the normal and $\operatorname{Smad} 3(-/)$ mutant mice and stored at $-70^{\circ} \mathrm{C}$ according to the manufacturer's protocol of the RNeasy Mini kit
(Qiagen, Inc., Valencia, CA, USA) followed by treatment with DNasel (Invitrogen; Thermo Fisher Scientific, Inc., Waltham, MA, USA). The quality and quantity of the RNA was analysed using a NanoDrop 2000 machine (Thermo Fisher Scientific, Inc.). Reverse transcription (RT) was performed using $0.5 \mu \mathrm{g}$ total RNA as a template. A ThermoScript ${ }^{\mathrm{TM}}$ RT-PCR System for First-Strand cDNA Synthesis and Platinum ${ }^{\circledR}$ Taq DNA Polymerase (both purchased from Thermo Fisher Scientific, Inc.) was used for the RT-PCR experiments according to the manufacturer's protocol. PCR was performed on $1 / 20$ of the RT product using the following primers (Sigma-Aldrich; EMD Millipore): Smad3 forward, 5'-TTCACAGACCCATCAAAC TCGGA-3' and reverse, 5'-CACTATCACTTAGGCACTCAG CA-3'; P53 forward, 5'-ACAGGACCCTGTCACCGAGACC-3' and reverse, 5'-GACCTCCGTCATGTGCTGTGAC-3'; COX-2 forward, 5'-CCCTTGGGTGTCAAAGGTAA-3' and reverse, 5'-GCCCTCGCTTATGATCTGTC-3'; and $\beta$-actin forward, 5'-CTAAGGCCAACCGTGAAAAGA-3' and reverse, 5'-CAGTAATCTCCTTCTGCATCC-3'. The cycles were run according to the manufacturer's protocol of the ThermoScript RT-PCR System for First-Strand cDNA Synthesis, and the PCR products were resolved on $2 \%$ agarose gels with ethidium bromide. The gels were observed and documented using a gel documentation unit (Gel Doc ${ }^{\mathrm{TM}}$ EZ System; Bio-Rad Laboratories, Inc., Hercules, CA, USA). All experiments were repeated three times.

\section{Results}

Smad3 mutant mice develop colorectal tumors. Homozygous mutant Smad3 mice were generated from the inbred and hybrid 

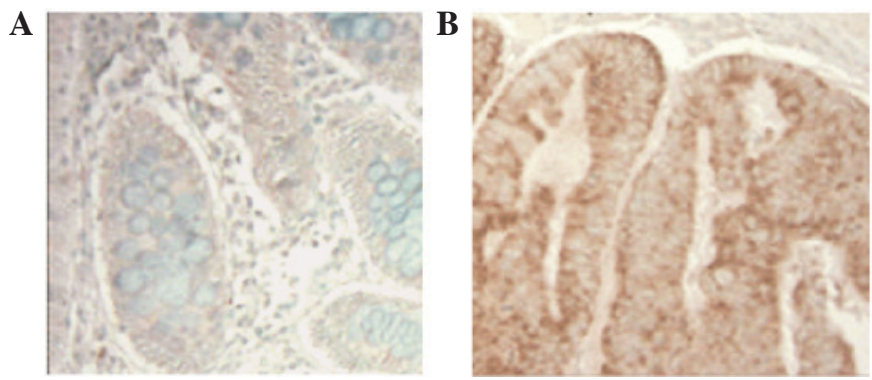

Figure 2. Immunohistochemistry with anti-COX-2 antibodies. (A) Few COX-2-positive cells were noted in the control tissue section. (B) COX-2 overexpression was observed in homozygous mutant Smad3 mouse tissue. Positive cells are indicated by brown staining. Representative images from three replicate experiments are presented here. Magnification, x20. COX-2, cyclooxygenase-2.

Smad3 mouse strains by intercrossing the appropriate heterozygotes. Based upon this protocol, 12 homozygous inbred $129 / \mathrm{Sv}$ mutant Smad3 mice were generated. The expression pattern of Smad3 in normal and homozygous mutant Smad3 (-/-) mice was identified by whole-mount in situ hybridization of embryos at day 11.5. The data is presented in Fig. 1. Between 20 and 22 weeks, $100 \%$ (10/10) of inbred Smad3 mutants began to exhibit signs of colon cancer, including rectal prolapse, and dilated large and small bowels, leading to apparent distress and indicating evidence of tumor formation. This appeared to indicate that homozygous mutant Smad3 mice develop colon cancer.

Overexpression of COX-2 in Smad3 mutant mice. Samples were prepared from normal and homozygous mutant Smad3 mice at the 22nd week for immunohistochemistry with COX-2 antibody as described in the Materials and Methods. The results of immunohistochemistry are presented in Fig. 2. Fig. 2B illustrates the overexpression pattern of COX-2 in homozygous mutant Smad3 mice. Positive staining in Smad3 mice was increased compared to the control, confirming the presence of overexpression of COX-2 in Smad3 mutant mice.

$R T$-PCR analysis. RNA was isolated from the normal and homozygous mutant Smad3 mice at the 22nd week for RT-PCR analysis as described in the Materials and Methods. The overexpression pattern of COX-2 in Smad3 mutant mice was investigated. Agarose gels produced following RT-PCR are presented in Fig. 3, which show the positive expression of P53 and COX-2 in homozygous mutant Smad3 mice.

\section{Discussion}

Dissection of the molecular pathway underlying colon cancer is key to understanding the specific involvement of various proteins. Studying molecular alterations and clinical outcomes is important in cancer research (16-22). Homozygous mutant Smad3 mice were generated and began to develop colon cancer from the 20th to 22 nd week. Based on the results of the present study, it was concluded that Smad3 was mutated and not expressed in the $\mathrm{Smad} 3$ (-/-) mutant mice. In addition, Smad3 expression was identified in various parts of the normal embryo, suggesting its importance. Smad3 is expressed in numerous developing tissues, with the highest levels observed in mesenchymal derivatives. In addition, Smad3 is expressed in the adult colon, with the highest levels observed in the

\section{Smad3 \\ Mutant Control}

Smad3

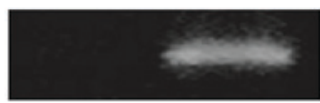

P53

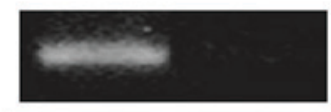

cox-2

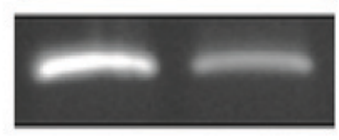

B-Actin

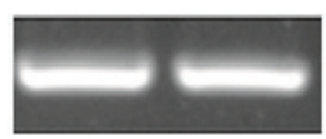

Figure 3. Reverse transcription-polymerase chain reaction analysis Overexpression profile of COX-2 with Smad3, P53 (along with the control $\beta$-actin) in the control and homozygous mutant Smad3 mice. Representative blots from three replicate experiments are presented here. COX-2, cyclooxygenase-2.

muscularis propria and the submucosa, and lower levels in the epithelium. Thus, Smad3 is a widely expressed TGF $\beta$ signaling intermediate (23).

Immunohistochemistry with COX-2 antibody revealed overexpression in the homozygous Smad3 mutant mouse. By comparing immunohistochemical staining in the control and Smad3 samples, COX-2 overexpression was clearly observed, and low levels of expression of COX-2 were observed in the control sample. In addition, following the development of colon cancer in homozygous mutant Smad3 mice, COX-2 was overexpressed.

In order to validate the immunohistochemistry data, RT-PCR was performed. The results of RT-PCR led to the conclusion that COX-2 is overexpressed in homozygous mutant Smad3 mice. In addition, P53 was upregulated in the homozygous mutant Smad3 mice compared with the control. It has been previously reported that P53 is upregulated in cancer cells (24). In the present study, P53 was upregulated in the homozygous mutant Smad3 mice, appearing to demonstrate that these mice will go on to develop colon cancer. Furthermore, overexpression of COX-2 was also observed, therefore a link between P53 and COX-2 overexpression was inferred. Due to the results of the immunohistochemistry and RT-PCR analyses, it was concluded and validated that $\mathrm{Smad} 3$ mutant mice develop colon cancer with overexpression of COX-2. 
The results of the present study indicate that a link may exist between Smad3 mutant mice, colon cancer and COX-2. In addition, an overexpression pattern of COX-2 in Smad3 mutant mice, which developed colon cancer, was identified. There is the potential that COX-2 may be a good marker for the diagnosis of colon cancer during early stages.

\section{Acknowledgements}

The present study was financially supported by Zhejiang Medicines Health Science and Technology Program (grant no., 2013KYB046) and the National Natural Science Foundation of China (grant no., 81372210). The authors would like to thank the Institutional Review Ethical Board Approval Committee for the successful completion of this project.

\section{References}

1. Potter JD, Slattery ML, Bostick RM and Gapstur SM: Colon cancer: a review of the epidemiology. Epidemiol Rev 15: 499-545, 1993.

2. Siegel R, Desantis C and Jemal A: Colorectal cancer statistics, 2014. CA Cancer J Clin 64: 104-117, 2014.

3. Tomlinson I, Ilyas M and Novelli M: Molecular genetics of colon cancer. Cancer Metastasis Rev 16: 67-79, 1997.

4. Zhu Y, Richardson JA, Parada LF and Graff JM: Smad3 mutant mice develop metastatic colorectal cancer. Cell 94: 703-714, 1998.

5. Oshima M, Oshima H and Taketo MM: TGF-beta receptor type II deficiency results in defects of yolk sac hematopoiesis and vasculogenesis. Dev Biol 179: 297-302, 1996.

6. Liu X, Sun Y, Constantinescu SN, Karam E, Weinberg RA and Lodish HF: Transforming growth factor beta-induced phosphorylation of Smad3 is required for growth inhibition and transcriptional induction in epithelial cells. Proc Natl Acad Sci USA 94: 10669-10674, 1997.

7. Graff JM, Bansal A and Melton DA: Xenopus Mad proteins transduce distinct subsets of signals for the TGF beta superfamily. Cell 85: 479-487, 1996.

8. Brown JR and DuBois RN: COX-2: A molecular target for colorectal cancer prevention. J Clin Oncol 23: 2840-2855, 2005.

9. Soumaoro LT, Uetake H, Higuchi T, Takagi Y, Enomoto M and Sugihara K: Cyclooxygenase-2 expression: A significant prognostic indicator for patients with colorectal cancer. Clin Cancer Res 10: 8465-8471, 2004.

10. Buchanan FG and DuBois RN: Connecting COX-2 and Wnt in cancer. Cancer Cell 9: 6-8, 2006.
11. Humphreys BD, Valerius MT, Kobayashi A, Mugford JW, Soeung S, Duffield JS, McMahon AP and Bonventre JV: Intrinsic epithelial cells repair the kidney after injury. Cell Stem Cell 2: 284-291, 2008

12. National Research Council (US) Committee for the Update of the Guide for the Care and Use of Laboratory Animals: Guide for the Care and Use of Laboratory Animals. 8th edition. National Academies Press (US), Washington DC, 2011.

13. Shea K and Geijsen N: Dissection of $6.5 \mathrm{dpc}$ mouse embryos. J Vis $\operatorname{Exp}(2)$ e160: 10.3791/160, 2007

14. Hogan B, Costantini F and Lacy E (eds): Manipulating the Mouse Embryo: A Laboratory Manual. 1st edition. Cold Spring Harbor Laboratory Press, NY, pp55-60, 1986.

15. Zhong $X$, Wang $H$ and Jian $X$ : Expression of matrix metalloproteinases- 8 and -9 and their tissue inhibitor in the condyles of diabetic rats with mandibular advancement. Exp Ther Med 8: 1357-1364, 2014.

16. Ogino S, Meyerhardt JA, Cantor M, Brahmandam M, Clark JW, Namgyal C, Kawasaki T, Kinsella K, Michelini AL, Enzinger PC, et al: Molecular alterations in tumors and response to combination chemotherapy with gefitinib for advanced colorectal cancer. Clin Cancer Res 11: 6650-6656, 2005.

17. de Heer P, Gosens MJ, de Bruin EC, Dekker-Ensink NG, Putter H, Marijnen CA, van den Brule AJ, van Krieken JH, Rutten HJ, Kuppen PJ and van de Velde CJ; Dutch Colorectal Cancer Group: Cyclooxygenase 2 expression in rectal cancer is of prognostic significance in patients receiving preoperative radiotherapy. Clin Cancer Res 13: 2955-2960, 2007.

18. Zlobec I, Terracciano LM and Lugli A: Local recurrence in mismatch repair-proficient colon cancer predicted by an infiltrative tumor border and lack of CD8+ tumor-infiltrating lymphocytes. Clin Cancer Res 14: 3792-3797, 2008.

19. Henry LR, Lee HO, Lee JS, Klein-Szanto A, Watts P, Ross EA, Chen WT and Cheng JD: Clinical implications of fibroblast activation protein in patients with colon cancer. Clin Cancer Res 13: 1736-1741, 2007.

20. Ginty F, Adak S, Can A, Gerdes M, Larsen M, Cline H, Filkins R, Pang Z, Li Q and Montalto MC: The relative distribution of membranous and cytoplasmic met is a prognostic indicator in stage I and II colon cancer. Clin Cancer Res 14: 3814-3822, 2008.

21. Benson AB III: New approaches to assessing and treating early-stage colon and rectal cancers: Cooperative group strategies for assessing optimal approaches in early-stage disease. Clin Cancer Res 13: 6913s-6920s, 2007.

22. Morris M, Platell C and Iacopetta B: Tumor-infiltrating lymphocytes and perforation in colon cancer predict positive response to 5-fluorouracil chemotherapy. Clin Cancer Res 14: 1413-1417, 2008

23. Zhu Y, Richardson JA, Parada LF and Graff JM: Smad3 mutant mice develop metastatic colorectal cancer. Cell 94: 703-714, 1998.

24. He ZY, Shi CB, Wen H, Li FL, Wang BL and Wang J: Upregulation of p53 expression in patients with colorectal cancer by administration of curcumin. Cancer Invest 29: 208-213, 2011. 